\title{
Evaluation of electrochemotherapy in the management of apocrine gland anal sac adenocarcinomas in dogs: A retrospective study
}

\author{
Paola Valenti ${ }^{1,2^{*}}$, Francesco Menicagli ${ }^{3}$, Alfonso Baldi ${ }^{4,5}$, Gabriele Barella $^{1}$, Chiara Catalucci ${ }^{1}$, Valeria Attorri ${ }^{2}$ and \\ Enrico P. Spugnini ${ }^{5}$ \\ ${ }^{1}$ Clinica Veterinaria Malpensa, Samarate, Italy \\ ${ }^{2}$ Ospedale Veterinario i Portoni Rossi, Zola Predosa, Italy \\ ${ }^{3}$ Clinica Veterinaria Giaconella, Roma, Italy \\ ${ }^{4}$ Department of Environmental, Biological, Pharmaceutical Sciences and Technologies, University of Campania "L. \\ Vanvitelli", Caserta, Italy \\ ${ }^{5}$ Biopulse Srl, Naples, Italy
}

\begin{abstract}
Background: Electrochemotherapy (ECT) combines the administration of anticancer drugs with the delivery of electric pulses, thus increasing the drug uptake through the cell membranes, resulting in increased efficacy.

Aim: The aim of our study was to describe the tolerability and efficacy of ECT alone or in association with other treatment modalities for the management of apocrine gland anal sac adenocarcinoma (AGASAC).

Methods: Medical records of dogs with a diagnosis of AGASAC that were treated with ECT alone or in combination with surgery/chemotherapy were retrospectively evaluated. Each dog received $20 \mathrm{mg} / \mathrm{m}^{2}$ of bleomycin intravenously. Based on the clinician's decision, the primary tumor or tumor bed was also infiltrated with cisplatin at the dose of 0.5 $\mathrm{mg} / \mathrm{cm}^{2}$. Trains of permeabilizing biphasic electric pulses were then applied under general anesthesia.

Results: Ten dogs were enrolled in the study. Of those $10 \mathrm{dogs}$, only one received ECT for treatment of microscopic local disease, while in six cases ECT was the only treatment modality. In three dogs, ECT was followed by systemic medical treatment. Six dogs $(60 \%)$ had a partial response (PR), three dogs $(30 \%)$ had stable disease, and one dog treated for microscopic disease did not show any sign of local relapse for 305 days after treatment, being still alive and in complete remission at the time of writing this article. The median time to progression was 303 days and the median survival time was 365 days. The treatment was well tolerated and local side effects were minimal. No systemic effects were documented.

Conclusion: This preliminary study suggests that ECT may be beneficial for dogs with AGASAC and could be a useful addition to the current therapeutic options in consideration of its low cost, limited toxicity, and ease of administration. Keywords: Anal gland anal sac adenocarcinoma, bleomycin, cisplatin, dog, electrochemotherapy.
\end{abstract}

\section{Introduction}

Apocrine gland anal sac adenocarcinoma (AGASAC) accounts for $17 \%$ of perianal malignant tumors and $2 \%$ of all skin and subcutaneous tumors in dogs (Goldschmidt and Shofer, 1992).

Metastasis at the time of diagnosis is reported in $26 \%-96 \%$ of dogs, with $26 \%-89 \%$ of the dogs having metastasis in regional lymph nodes (LN) and $0 \%-$ 42\% at distant sites (Meuten et al., 1981; Polton and Brearley, 2007; Pradel et al., 2018). Paraneoplastic hypercalcemia is also a common finding, occurring in $16 \%-53 \%$ of affected patients (Meuten et al., 1981, 1983; Polton and Brearley, 2007; Messinger et al., 2009; Pradel et al., 2018).

A staging system (ranging from stage 1 to stage 4), in which the disease is classified according to the size of the primary tumor, the presence and size of any metastatic LNs, and the presence of distant metastasis, has been validated and is correlated with the prognosis, with stages $3 \mathrm{~b}$ and 4 having the worst prognosis (Polton and Brearley, 2007).

Several therapeutic options have been described, including surgery, radiation therapy (RT), chemotherapy, and tyrosine kinase inhibitors use (Potanas et al., 2015; Barnes and Demetriou, 2017; Meier et al., 2017; Elliott, 2019), with surgery being considered the first option for dogs with non-metastatic AGASAC or metastatic AGASAC in regional LNs (Potanas et al., 2015; Barnes and Demetriou, 2017).

Electrochemotherapy (ECT) is an anticancer therapy that combines the administration of anticancer drugs with permeabilizing electric pulses, which causes transient perturbation and rearrangement of the cell membrane that result in increased cross-flow through the cytoplasmic membrane of otherwise low permeant molecules, such as bleomycin and cisplatin (Silve and Mir, 2011). The improved chemotherapy uptake by cancer cells induces multiple DNA damage that 
overcomes their ability to repair which ultimately causes apoptosis (Silve and Mir, 2011).

The use of ECT in one case of incompletely excised AGASAC resulted in complete remission (CR), with the dog being still alive and disease-free for 18 months after treatment (Spugnini et al., 2008). In that single case, ECT was well tolerated by the dog and neither systemic nor local side effects were reported.

The aim of this study was therefore to evaluate the tolerability and efficacy of ECT in a cohort of dogs with AGASAC treated by ECT alone or in combination with other treatment strategies.

\section{Materials and Methods}

Medical records of three different institutions were retrospectively searched for client-owned dogs with cytologically or histopathologically confirmed diagnosis of AGASAC that underwent treatment with ECT alone or in association with other treatment modalities between 2014 and 2019.

Dogs staging consisted of a complete blood cell count, serum biochemical profile, and three-view thoracic radiographs combined with abdominal ultrasonography or whole-body contrast enhanced CT scan.

The presence of lymphadenomegaly in the sublumbar region (medial iliac and lumbar LNs) and pelvic system (hypogastric and sacral LNs) was recorded and ultrasound (US)-guided LN fine needle aspirate was performed based on the feasibility of the procedure.

Tumors were staged according to a previously reported staging system (Polton and Brearley, 2007) (Table 1).

In all cases, surgery and/or RT were discussed as the primary treatment options with the owners and, if declined, ECT was offered.

ECT was also offered as an adjuvant treatment in case of residual disease after surgery and refusal of other adjuvant options such as re-excision or RT.

It was requisite for all dogs to have received at least two sessions of ECT, performed 2 weeks apart with a minimum follow-up of 30 days, which was considered adequate to evaluate clinical measurable response and development of side effects.

Bleomycin was intravenously injected as a bolus at the dose of $20 \mathrm{mg} / \mathrm{m}^{2}$ to obtain the broadest intratumoral drug distribution. Additionally, the primary tumor or the tumor bed was infiltrated with cisplatin with a dose of $0.5 \mathrm{mg} / \mathrm{cm}^{2}$ in case of tumors smaller than $5 \mathrm{~cm}$ in diameter, if necrotic areas were not suspected upon ultrasonographic examination, or if the tumor did not show an extensive blood network on doppler exam, to minimize the risk of chemotherapy leakage during the intralesional administration,

Five minutes after the chemotherapy injection, with animals under general anesthesia, sequences of eight biphasic pulses lasting $50+50 \mu \mathrm{sec}$ each were delivered to the primary tumor/tumor bed via clamp electrodes and to the metastatic LN under US guidance via two-needle $45-\mathrm{S}$ shielded electrodes at a voltage of 1,000-1,300 V/cm, depending on tumor electrical conduction as measured by the clinical electroporator (Onkodisruptor $\circledast$ ).

Response to treatment was defined by the primary clinician's assessment combined with US reexaminations at regular intervals, based on the Veterinary Cooperative Oncology Group Response Evaluation Criteria in Solid Tumours (VCOG RECIST) criteria, and classified as complete response (CR), partial response (PR), stable disease (SD), or progressive disease (Nguyen et al., 2015).

Time to progression (TTP) was defined as the interval between the first ECT session and the relapse of the disease, as defined by RECIST.

The median survival time (MST) was defined as the time in days since ECT was started until death due to any other cause, and was calculated according to the Kaplan-Meier method.

In case of death, due to other causes without signs of disease progression and in case of animals still alive without signs of disease progression or lost to followup, the dogs were censored for TTP analysis.

Tolerability of the treatment was assessed based on the development of any local or systemic side effect, classified by VCOGs Criteria (Veterinary Cooperative Oncology Group, 2016).

Ethical approval

All procedures were performed in accordance with institutional guidelines under the control of the Italian Ministry of Public Health (Italian Law D.lgs 26/2014).

\section{Results}

A total of 10 dogs were included in the study (Table 2), breeds distribution included two German Shepherds, one Dachshund, one Golden Retriever, one Labrador Retriever, one Pit Bull, and one Pointer. Three dogs were mixed breed. Regarding sex and age, three dogs

Table 1. Clinical stage scheme.

\begin{tabular}{cccc}
\hline Clinical stage & $\boldsymbol{T}$ & $\boldsymbol{N}$ & $\boldsymbol{M}$ \\
\hline 1 & $<2.5-\mathrm{cm}$ max diameter & None & None \\
2 & $>2.5-\mathrm{cm}$ max diameter & None & None \\
$3 \mathrm{a}$ & Any $T$ & Present,$<4.5-\mathrm{cm}$ max diameter & None \\
$3 \mathrm{~b}$ & Any $T$ & Present, $>4.5-\mathrm{cm}$ max diameter & None \\
4 & Any $T$ & Any $N$ & Present \\
\hline
\end{tabular}


Table 2. Dogs' characteristics and outcomes.

\begin{tabular}{|c|c|c|c|c|c|c|c|c|c|c|c|}
\hline $\begin{array}{l}\text { Animal } \\
\text { number }\end{array}$ & Breed & Sex & Age & $\begin{array}{c}\text { Clinical } \\
\text { signs at } \\
\text { presentation }\end{array}$ & Stage & $\begin{array}{c}\text { Diagnostic } \\
\text { imaging/ } \\
\text { staging } \\
\text { modality }\end{array}$ & $\begin{array}{c}\text { Number } \\
\text { of ECT } \\
\text { sessions }\end{array}$ & $\begin{array}{c}\text { Response } \\
\text { to } \\
\text { treatment }\end{array}$ & TTP & MST & Cause of death \\
\hline 1 & $\begin{array}{l}\text { Golden } \\
\text { retriever }\end{array}$ & $\mathrm{MC}$ & 12 & $\begin{array}{l}\text { Perianal } \\
\text { mass }\end{array}$ & $3 B$ & $\begin{array}{c}\text { 3-view } \\
\text { thoracic } \\
\text { radiographs, } \\
\text { abdominal } \\
\text { US }\end{array}$ & 4 & SD & 292 & 384 & $\begin{array}{l}\text { Pulmonary } \\
\text { thromboembolism }\end{array}$ \\
\hline 2 & $\begin{array}{l}\text { Mixed } \\
\text { breed }\end{array}$ & FS & 9 & $\begin{array}{l}\text { Perianal } \\
\text { mass }\end{array}$ & $3 \mathrm{~B}$ & CT scan & 2 & SD & SD & Alive & Alive \\
\hline 3 & Pointer & Fs & 14 & $\begin{array}{l}\text { Perianal } \\
\text { mass }\end{array}$ & $3 \mathrm{~A}$ & CT scan & 2 & SD & 150 & 150 & Tumor-related \\
\hline 4 & $\begin{array}{l}\text { German } \\
\text { shepherd }\end{array}$ & FS & 12 & $\begin{array}{l}\text { Perianal } \\
\text { mass }\end{array}$ & $3 \mathrm{~A}$ & $\begin{array}{c}\text { 3-view } \\
\text { thoracic } \\
\text { radiographs, } \\
\text { abdominal } \\
\text { US }\end{array}$ & 3 & PR & 548 & 600 & Tumor-related \\
\hline 5 & $\begin{array}{l}\text { German } \\
\text { shepherd }\end{array}$ & FS & 10 & $\begin{array}{l}\text { Perianal } \\
\text { mass }\end{array}$ & $3 \mathrm{~A}$ & $\begin{array}{c}\text { 3-view } \\
\text { thoracic } \\
\text { radiographs, } \\
\text { abdominal } \\
\text { US }\end{array}$ & 7 & PR & PR & Alive & Alive \\
\hline 6 & Dachshund & FS & 10 & $\begin{array}{l}\text { Perianal } \\
\text { mass }\end{array}$ & $3 \mathrm{~B}$ & $\begin{array}{c}\text { 3-view } \\
\text { thoracic } \\
\text { radiographs, } \\
\text { abdominal } \\
\text { US }\end{array}$ & 4 & PR & 254 & 254 & Renal failure \\
\hline 7 & $\begin{array}{c}\text { Mixed } \\
\text { breed }\end{array}$ & FS & 11 & $\begin{array}{l}\text { Perianal } \\
\text { mass }\end{array}$ & 2 & $\begin{array}{c}\text { 3-view } \\
\text { thoracic } \\
\text { radiographs, } \\
\text { abdominal } \\
\text { US }\end{array}$ & 3 & PR & 300 & 365 & Tumor-related \\
\hline 8 & Pit Bull & $\mathrm{F}$ & 9 & $\begin{array}{l}\text { Perianal } \\
\text { mass }\end{array}$ & 2 & $\begin{array}{c}\text { 3-view } \\
\text { thoracic } \\
\text { radiographs, } \\
\text { abdominal } \\
\text { US }\end{array}$ & 3 & PR & 245 & 320 & Tumor-related \\
\hline 9 & $\begin{array}{c}\text { Mixed } \\
\text { breed }\end{array}$ & M & 13 & $\begin{array}{l}\text { Perianal } \\
\text { mass }\end{array}$ & 2 & $\begin{array}{c}\text { 3-view } \\
\text { thoracic } \\
\text { radiographs, } \\
\text { abdominal } \\
\text { US }\end{array}$ & 3 & PR & PR & 400 & $\begin{array}{c}\text { Other (age-related } \\
\text { problems) }\end{array}$ \\
\hline 10 & $\begin{array}{l}\text { Labrador } \\
\text { retriever }\end{array}$ & $\mathrm{MC}$ & 10 & $\begin{array}{l}\text { Perianal } \\
\text { mass }\end{array}$ & 2 & $\begin{array}{c}\text { 3-view } \\
\text { thoracic } \\
\text { radiographs, } \\
\text { abdominal } \\
\text { US }\end{array}$ & 2 & $\mathrm{CR}$ & CR & Alive & Alive \\
\hline
\end{tabular}

were male (two neutered) and seven were female (six spayed). The mean age was 11 years (range 9-14).

The major clinical complaint in all animals was the presence of a unilateral mass in the perineal region, which caused tenesmus in two dogs. In two cases, the diagnosis was made by fine needle aspirate of the primary tumor, while in the remaining cases it was made by histology, specifically by incisional biopsy in 
seven dogs and excisional biopsy in one. Two dogs were presented with elevated ionized calcium, 1.6 and 1.78 $\mathrm{mmol} / \mathrm{l}$ (reference range $1.2-1.5 \mathrm{mmol} / \mathrm{l}$ ), respectively. The hypercalcemia resolved without additional therapy after the second ECT session in both animals.

Two cases were staged by whole-body contrast enhanced CT scan, while the remaining eight were staged with a combination of three-view thoracic radiographs and abdominal US.

LN metastases were cytologically detected in three dogs in the sublumbar region, being classified as stage $3 \mathrm{~b}$, and in one dog in the inguinal LN, being classified as stage $3 \mathrm{a}$, while the remaining dogs were classified as stage 2 .

Out of those ten dogs, only one dog received ECT for treatment of microscopic local disease, while in the remaining cases ECT was used to treat the primary macroscopic tumor (Fig. 1A and B) and, if present, the metastatic LNs. In three dogs, ECT was followed by systemic medical treatment including carboplatin, mitoxantrone, and toceranib phosphate.

The number of ECT sessions ranged from a minimum of two sessions in three dogs to a maximum of seven sessions in one animal, with a mean number of ECT sessions being three. The treatment was well tolerated and side effects were limited to short-lasting (3-4 days) local inflammation in six dogs (VCOG Grade 1) that was solved with the administration of an anti-inflammatory drug. No systemic side effects were noted.

In terms of response, six dogs $(60 \%)$ had PR, three dogs $(30 \%)$ had SD, and the dog treated for microscopic disease did not show any sign of local relapse for 305 days after treatment, being still alive and disease-free at the time of writing.

Seven dogs were dead at the time of the last follow-up. Four $(40 \%)$ died of tumor-related causes (development of distant metastasis), three (30\%) died of unrelated causes (pulmonary thromboembolism, renal failure, and age-related problems, respectively), and three dogs were still alive, showing CR, PR, and SD.

Median TTP was 303 days (95\% CI: 257-381) and the overall MST was 365 days (95\% CI: 258-449) (Fig. 2).

\section{Discussion}

Several therapeutic options for AGASAC have been proposed, including surgery, RT, medical treatment, or a combination of all these techniques (Potanas et al., 2015; Barnes and Demetriou, 2017; Meier et al., 2017; Elliott, 2019). Surgery is considered the best treatment option for dogs with non-metastatic or metastatic in the regional LN AGASAC (Skorupski et al., 2018), and the reported disease-free intervals (DFIs) for dogs treated surgically, with or without adjuvant therapy, range from 262 to 443 days (Turek et al., 2003; Potanas et al., 2015; Wouda et al., 2016).

Several studies have reported shorter median DFIs in dogs with LN metastasis upon diagnosis (134-197 days) compared to dogs without LN metastasis (529760 days) (Turek et al., 2003; Wouda et al., 2016). Also, the overall survival time was reported to be shorter: 293-448 days in dogs with LN metastasis compared to 529-925 days in dogs without metastasis (Turek et al., 2003; Potanas et al., 2015; Wouda et al., 2016).

A surgical approach is not always possible in case of advanced stages of the disease $(3 \mathrm{~b}, 4)$, or can be declined by owners due to the guarded to poor prognosis. In these cases, non-surgical strategies such as RT and/or

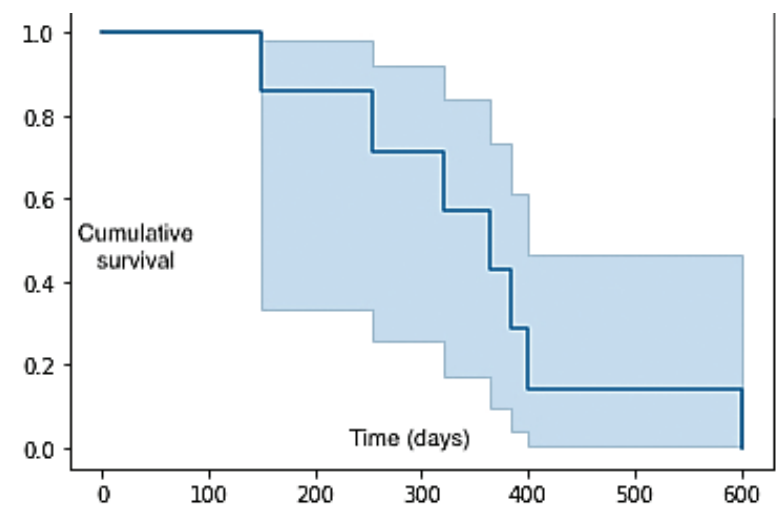

Fig. 2. Kaplan-Meier curve showing the overall MST of the population.
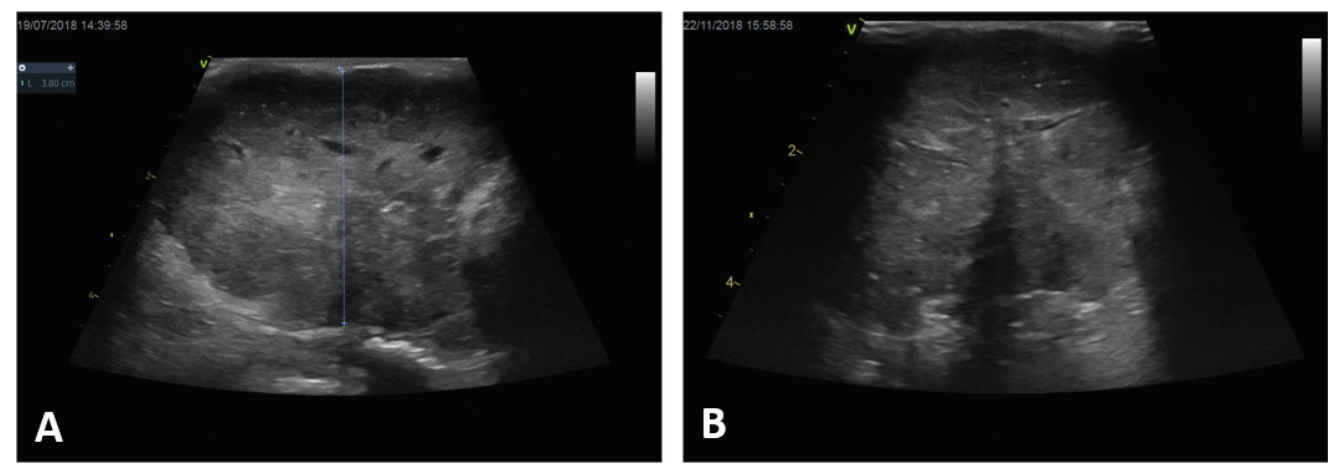

Fig. 1. Clinical outcome of a large anal sac carcinoma (A) at presentation and (B) after one session of ECT. Note the appearance of a large anechoic formation compatible with necrotic neoplasm. 
medical treatment are usually offered (McQuown et al., 2017; Meier et al., 2017; Elliott, 2019).

Hypofractionated RT in 13 dogs with stage $3 \mathrm{~b}$ AGASAC resulted in a progression-free interval (PFI) and MST, respectively, of 347 and 447 days. PFI and MST of surgical patients were significantly inferior compared to patients treated with RT (Meier et al., 2017). Nevertheless, since cost and availability can make RT infeasible, alternative treatment modalities to achieve local tumor control are desirable.

The role of chemotherapy in AGASAC remains controversial: indeed, chemotherapy has traditionally been recommended for the treatment of canine AGASAC because of the high risk of metastasis, although several studies failed to demonstrate a survival advantage (Polton and Brearley, 2007; Potanas et al., 2015; Wouda et al., 2016).

ECT is an anticancer therapy that associates the systemic and/or local administration of chemotherapy agents with the delivery of permeabilizing electric pulses with specific amplitude, duration, and waveforms (Spugnini et al., 2016, 2017). This strategy is helpful to increase the efficacy of lipophobic drugs that often have a narrow therapeutic index, thus minimizing patient toxicosis while maintaining adequate anticancer efficacy (Spugnini et al., 2016). ECT has been described as a useful adjuvant therapy for several tumor types, including squamous cell carcinoma, mast cell tumor, and soft tissue sarcoma (Spugnini et al., 2011, 2015, 2019).

ECT also represents an alternative method to surgery for treating solid tumors, especially in cases where owners decline surgery or if the tumors are difficult to excise due to their location, such as in the perianal region (Spugnini and Porrello, 2003; Tozon et al., 2005). ECT can also be repeated several times, as long as the clinical response is achieved and can also be safely combined with other treatments, such as chemotherapy, making this treatment particularly appealing for patients with a macroscopic disease or metastatic disease, where the main goal is to achieve a good balance between tumor control and quality of life (Spugnini and Baldi, 2019). In our study, all but one dog was treated for macroscopic disease and the measurable response was documented in $60 \%$ of them, with the overall median TTP being 303 days and the overall MST being 365 days, confirming that ECT was effective in dogs with macroscopic disease. These data are similar to previously reported results in dogs with measurable AGASAC treated with hypofractionated RT, in which the median progressionfree survival was 289 days and the overall MST was 329 days (McQuown et al., 2017).

Six of our dogs were classified as stage 2, which is not typically considered an advanced stage disease, and in all included cases either surgery or RT was offered as the first-line treatment. In the majority of these animals, surgery was declined by owners due to related side effects, such as wound dehiscence, rectal perforation, rectocutaneous fistulation, and transient fecal incontinence, while RT was declined due to financial issues. ECT was therefore performed mainly for macroscopic disease as an alternative treatment, allowing for local tumor control with minimal side effects.

To confirm the biological activity of ECT, we documented resolution of hypercalcemia in two dogs after two sessions of ECT without the need of additional systemic treatments, such as diuresis, corticosteroids, or bisphosphonates.

The treatment was well tolerated in the study population and acute side effects, mainly represented by local inflammation, were transient and easily managed. No late side effects were reported.

The major limitations of this study are its retrospective nature and the small number of enrolled cases.

Also, $80 \%$ of the dogs were staged through abdominal US combined with thoracic radiographs, which bears the risk, when compared to staging performed by $\mathrm{CT}$, of underestimating the stage of the disease and potentially leading to suboptimal treatment in patients with advanced-stage disease, such as stage 4 , where systemic treatment could be considered or owners are more willing to pursue systemic rather than local therapies. A high variation in MST with 1,205 days, 722 days, 492/294 days, and 71 days for stage 1, 2, $3 \mathrm{a} / \mathrm{b}$, and 4 AGASAC, respectively, has been reported (Polton and Brearley, 2007), with higher stages being associated with the worst prognosis; this should be taken into account when evaluating the results of this study since in our populations the stages ranged from 2 to $3 \mathrm{~b}$, with stage 2 being the most represented. Hence, the high MST that we reported may have been influenced by the stage of the disease, leading to an overestimation of the efficacy of ECT.

Due to the low number of enrolled animals, we could not stratify our population and therefore draw any conclusion on the different outcome of different clinical stages treated by ECT.

Another limitation of the present study is the lack of case standardization since in four animals ECT was combined with other treatment strategies, specifically surgery in one dog and chemotherapy in three dogs: these additional therapies could have been a confounding factor in the clinical outcome of these animals.

Further studies including a larger population and investigating the efficacy of ECT alone or in combination with other treatment strategies in patients with advanced disease are warranted.

In conclusion, our results suggest that ECT may improve or palliate clinical signs related to AGASAC, even when metastasis to the regional LNs is present. The tolerability and feasibility of ECT make this treatment a valuable option for dogs with AGASAC whenever 
the owner declines other therapeutic strategies, such as surgery and/or RT, due to financial issues or related side effects.

\section{Acknowledgments}

The authors thank Dr Guy Beretich for reviewing the manuscript.

\section{Conflict of interest}

Enrico P. Spugnini and Alfonso Baldi are the stockholders of Biopulse S.r.l.

\section{Authors' contributions}

EPS and PV conceived and supervised the study; FM and GB performed the ultrasonographic evaluation of the anal sac neoplasms and assisted with the ultrasonographic guidance for the ECT sessions; AB performed the histopathology analysis of most clinical cases; and CC and VA were directly responsible of the clinical cases and assisted during clinical outcome follow-up and data collection.

\section{References}

Barnes, D.C., and Demetriou, J. L. 2017. Surgical management of primary, metastatic and recurrent anal sac adenocarcinoma in the dog: 52 cases. J. Small Anim. Pract. 58(5), 263-268.

Elliott, J.W. 2019. Response and outcome following toceranib phosphate treatment for stage four anal sac apocrine gland adenocarcinoma in dogs: 15 cases (2013-2017). J. Am. Vet. Med. Assoc. 254(8), 960-966.

Goldschmidt, M.H. and Shofer, F.S. 1992. Skin tumors of the dog and cat. Oxford, UK: Pergamon Press.

McQuown, B., Keyerleber, M.A., Rosen, K., McEntee, M.C. and Burgess, K.E. 2017. Treatment of advanced canine anal sac adenocarcinoma with hypofractionated radiation therapy: 77 cases (19992013). Vet. Comp. Oncol. 15, 840-851.

Meier, V., Polton, G., Cancedda, S., Roos, M., Laganga, P., Emmerson, T. and Rohrer Bley, C. 2017. Outcomes in dogs with advanced (stage $3 \mathrm{~b}$ ) anal sac gland carcinoma treated with surgery or hypofractionated radiation therapy. Vet. Comp. Oncol. 15, 1073-86.

Messinger, J.S., Windham, W.R. and Ward, C.R. 2009. Ionized hypercalcemia in dogs: a retrospective study of 109 cases (1998-2003). J. Vet. Intern. Med. 23, 514-519.

Meuten, D.J., Cooper, B.J., Capen, C.C., Kociba, G.J. and Cooper, B. J. 1981. Hypercalcemia associated with an adenocarcinoma derived from the apocrine glands of the anal sac. Vet. Pathol. 18, 454-471.

Meuten, D.J., Segre, G.V., Capen, C.C., Kociba, G.J., Voelkel, E.F., Levine, L., Tashjian, A.H. Jr, Chew, D.J. and Nagode, L.A. 1983. Hypercalcemia in dogs with adenocarcinoma derived from apocrine glands of the anal sac. Lab. Invest. 48, 428-434.

Nguyen, S.M., Thamm, D.H., Vail, D.M. and London, C.A. 2015. Response evaluation criteria for solid tumours in dogs (v1.0): a Veterinary Cooperative Oncology Group (VCOG) consensus document. Vet. Comp. Oncol. 13, 176-183.Polton, G.A. and Brearley, M.J. 2007. Clinical stage, therapy, and prognosis in canine anal sac gland carcinoma. J. Vet. Intern. Med. 21, 274-280.

Potanas, C.P., Padgett, S. and Gamblin, R.M. 2015. Surgical excision of anal sac apocrine gland adenocarcinomas with and without adjunctive chemotherapy in dogs: 42 cases (2005-2011). 2015 J. Am. Vet. Med. Assoc. 246, 877-884.

Pradel, J., Berlato, D., Dobromylskyj, M. and Rasotto, R. 2018. Prognostic significance of histopathology in canine anal sac gland adenocarcinomas: preliminary results in a retrospective study of 39 cases. Vet. Comp. Oncol. 16, 518-528.

Silve, A. and Mir, L.M. 2011. Cell, electropermeabilization and cellular uptake of small molecules: the electrochemotherapy concept. In Clinical aspects of electroporation, 1st ed. Eds., Kee, S.T., Gehl, J., Lee, E.W., Berlin, Germany: Springer, pp: 69-82.

Skorupski, K.A., Alarcòn, C.N., de Lorimier, L. P., LaDouceur, E. E. B., Rodriguez, C. O., Rebhun, R. B. 2018. Outcome and clinical, pathological, and immunohistochemical factors associated with prognosis for dogs with early-stage anal sac adenocarcinoma treated with surgery alone: 34 cases (2002-2013). J. Am. Vet. Med. Assoc. 253, 84-91.

Spugnini, E.P. and Baldi A. 2019. Electrochemotherapy in veterinary oncology: state-of-the-art and perspectives. Vet. Clin. North Am. Small Anim. Pract. 49(5), 967-979.

Spugnini, E.P., Azzarito, T., Fais, S., Fanciulli, M. and Baldi, A. 2016. Electrochemotherapy as first line cancer treatment: experiences from veterinary medicine in developing novel protocols. Curr. Cancer. Drug. Targets. 16, 43-52.

Spugnini, E.P., Dotsinsky, I., Mudrov, N., Bufalini, M., Giannini, G., Citro, G., Feroce, F. and Baldi, A. 2008. Adjuvant electrochemotherapy for incompletely excised anal sac carcinoma in a dog. In Vivo. 22, 47-50.

Spugnini, E.P., Fais, S., Azzarito, T. and Baldi, A. 2017. Novel Instruments for the Implementation of Electrochemotherapy Protocols: From Bench Side to Veterinary Clinic. J. Cell Physiol. 232, 490-495.

Spugnini, E.P., Pizzuto, M., Filipponi, L., Romani, B., Vincenzi, F., Menicagli, A., Lanza, R., De Girolamo, R., Lomonaco, M., Fanciulli, Spriano, G. and Baldi, A. 2015. Electroporation enhances bleomycin efficacy in cats with periocular carcinoma and advanced squamous cell carcinoma of the head. J. Vet. Intern. Med. 29, 1368-75.

Spugnini, E.P., Porrello, A. 2003. Potentiation of chemotherapy in companion animals with spontaneous large neoplasms by application of 
electric pulses. J. Exp. Clin. Cancer Res. 22, 571580.

Spugnini, E.P., Vincenzi, B., Amadio, B. and Baldi, A. 2019. Adjuvant electrochemotherapy with bleomycin and cisplatin combination for canine soft tissue sarcomas: a study of 30 cases. Open Vet. J. 9, 88-93.

Spugnini, E.P., Vincenzi, B., Citro, G., Dotsinsky, I., Mudrov, T. and Baldi A. 2011. Evaluation of cisplatin as an electrochemotherapy agent for the treatment of incompletely excised mast cell tumors in dogs. J. Vet. Intern. Med. 25, 407-411.

Tozon, N., Kodre, V., Sersa, G., Cemazar, M. 2005. Effective treatment of perianal tumors in dogs with electrochemotherapy. Anticancer Res. 25, 839-846.
Turek, M.M., Forrest, L.J., Adams, W.M., Helfand S.C. and Vail, D.M. 2003. Postoperative radiotherapy and mitoxantrone for anal sac adenocarcinoma in the dog: 15 cases (1991-2001). Vet. Comp. Oncol. 1, 94-104.

Veterinary Cooperative Oncology Group. 2016. Common terminology criteria for adverse events (VCOG- CTCAE) following chemotherapy or biological antineoplastic therapy in dogs and cats v1.1. Vet. Comp. Oncol. 14, 417-446.

Wouda, R.M., Borrego, J., Keuler, N.S. and Stein, T. 2016. Evaluation of adjuvant carboplatin chemotherapy in the management of surgically excised anal sac apocrine gland adenocarcinoma in dogs. Vet. Comp. Oncol. 14, 67-80. 